\title{
Familial X-linked mental retardation with an X chromosome abnormality
}

\author{
J. HARVEY, C. JUDGE, and S. WIENER \\ From St. Nicholas Hospital, Carlton, Victoria, Australia
}

SUMMARY An X-linked pattern of transmission observed in four families with familial mental retardation in several generations was associated with a probable secondary constriction at the distal end of the $\mathrm{q}$ arms of the $\mathrm{X}$ chromosome. Twenty retarded males and no retarded females were observed. All available live retarded males and most of their normal mothers were found to have the abnormal $\mathrm{X}$ chromosome. The marker chromosome was shown to be the $\mathrm{X}$ chromosome in each case by Giemsa banding. In affected male and female carriers the marker chromosome varied in appearance and was not present in all metaphases.

The significance of this study in relation to previously reported pedigrees showing non-specific $\mathrm{X}$-linked mental retardation is discussed.

The higher incidence of mental retardation in males and, in particular, reports of family studies where there are only affected males, indicate a mode of transmission compatible with X-linked inheritance (Martin and Bell, 1943; Renpenning et al, 1962; Dunn et al, 1962/1963; Snyder and Robinson, 1969). With the exception of one report by Lubs (1969) no association between this X-linked pattern of inheritance and any observable abnormality of the $\mathrm{X}$ chromosome has been so far reported. In this report a family of 4 retarded males and 2 nonretarded females had a structural abnormality of the $\mathrm{X}$ chromosome described as a secondary constriction or fragile site.

We report here 4 families with a similarly abnormal $\mathbf{X}$ chromosome which segregated through several generations in each family and resulted in a total of 20 retarded males and 11 non-retarded female carriers. The propositus in each of these 4 families was found to have the structurally abnormal $\mathrm{X}$ chromosome during a survey of mildly retarded institutionalized males.

\section{Materials and methods}

Blood samples were collected from available family members and lymphocyte cultures established by standard techniques. All cultures were

Received for publication 10 February 1976 incubated for 3 days and colchicine added two and a half hours before harvesting.

Air-dried preparations were stained with Giemsa and the number of metaphases with the structurally abnormal $\mathrm{X}$ chromosome was counted. One hundred metaphases were analysed in each case. In those subjects in whom the marker chromosome was found, slides were treated with trypsin to produce G-bands (Birner and Wiener, 1975) in order to show that the chromosome involved was the $\mathrm{X}$ chromosome. Telomeric bands were studied by observing fluorescence with acridine orange (Dutrillaux, 1973). Culture time and duration of colchicine treatment were varied to determine the effect of culture technique on the marker chromosome.

Pedigrees of the families are shown in Fig. 1, 2, 3, and 4 and cytogenetic data are recorded in the Table.

\section{Case reports}

\section{Family A (Fig. 1)}

The family is known (Roboz and Pitt, 1969) through 4 generations and shows retardation in 3 generations. In generation II all 5 males in a sibship of 10 were retarded whereas all 5 females had normal IQs. There was no consanguinity. Members of this family were as follows:

Case 1.1. A 59-year-old man who had been in a mental hospital in New Zealand since the age of 16 years. He was moderately retarded and had no congenital abnormalities. 


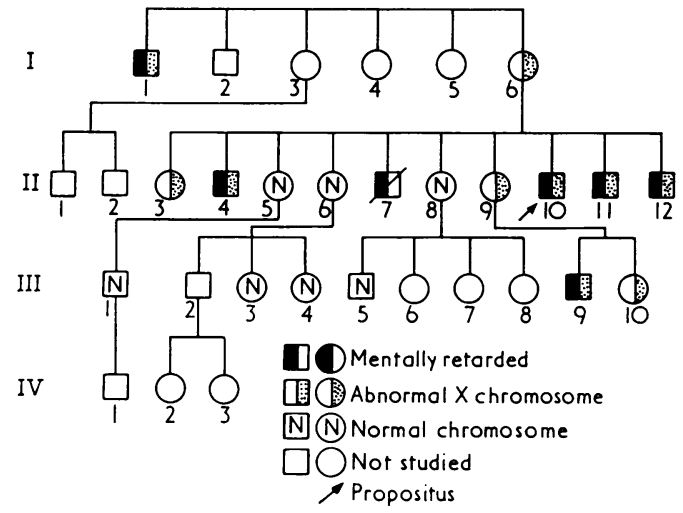

Fig. 1. Pedigree of Family A.

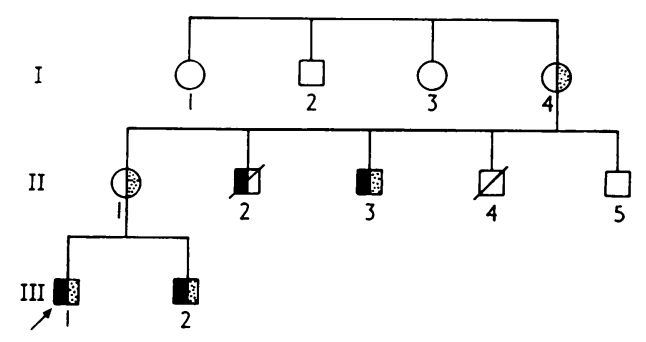

FIG. 2. Pedigree of Family B.

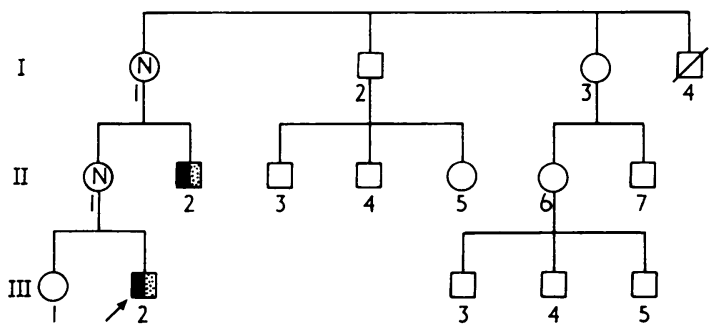

FIg. 3. Pedigree of Family C.
TABLE

PERCENTAGE OF MARKER X CHROMOSOME

\begin{tabular}{|c|c|c|c|}
\hline Family & $\begin{array}{l}\text { Case } \\
\text { No. }\end{array}$ & Sex & $\begin{array}{l}\% \text { of Cells with } \\
\text { Marker X Chromosome }\end{array}$ \\
\hline A & $\left\{\begin{array}{l}\text { I.1 } \\
\text { I.6. } \\
\text { II. } 3 \\
\text { II. } \\
\text { II.9 } \\
\text { II.10† } \\
\text { II.11 } \\
\text { II.12 } \\
\text { III.9 } \\
\text { III.10 }\end{array}\right.$ & $\begin{array}{l}\mathbf{M} \\
\mathbf{F} \\
\mathbf{M} \\
\mathrm{F} \\
\mathbf{M} \\
\mathbf{M} \\
\mathbf{M} \\
\mathbf{M} \\
\mathrm{F}\end{array}$ & $\begin{array}{l}18 \\
2 \\
7 \\
36 \\
8 \\
22,25,36^{*} \\
22,50,31,26^{*} \\
37 \\
21,19 * \\
17\end{array}$ \\
\hline B & $\left\{\begin{array}{l}\text { I.4 } \\
\text { II.1 } \\
\text { II.3 } \\
\text { III. } 1 \dagger \\
\text { III.2 }\end{array}\right.$ & $\begin{array}{l}\mathrm{F} \\
\mathrm{F} \\
\mathbf{M} \\
\mathbf{M} \\
\mathbf{M}\end{array}$ & $\begin{array}{r}6 \\
24 \\
40 \\
35 \\
34\end{array}$ \\
\hline C & $\left\{\begin{array}{l}\text { I.1 } \\
\text { II..1 } \\
\text { II.2 } \\
\text { III.2t }\end{array}\right.$ & $\begin{array}{l}\mathrm{F} \\
\mathrm{F} \\
\mathrm{M} \\
\mathrm{M}\end{array}$ & $\begin{array}{r}0 \\
0 \\
22 \\
8\end{array}$ \\
\hline D & $\left\{\begin{array}{l}\text { II.14 } \\
\text { III.16 } \\
\text { II.17† }\end{array}\right.$ & $\begin{array}{l}M \\
M \\
M\end{array}$ & $\begin{array}{l}13 \\
33 \\
41\end{array}$ \\
\hline
\end{tabular}

* Studied on more than one occasion. † Propositus.

Case II.4. A 50-year-old man who had been in a mental hospital because of mild retardation since the age of 13 years. He was physically normal apart from a mild degree of pectus excavatum.

Case II.7. A retarded man who lived in an institution for the retarded. He died of kidney disease at the age of 29 years.

Case II.10. He was 42 years of age and had been maintained in a centre for the retarded since the age of 4 years. He was moderately retarded and had large hands and feet. He had a pedunculated tumour in the lumbar region.

Case II.11. He was 40 years of age and had been maintained in a training centre for the retarded since the age of 6 years. He was physically normal. He had an intradermal naevus on the neck.

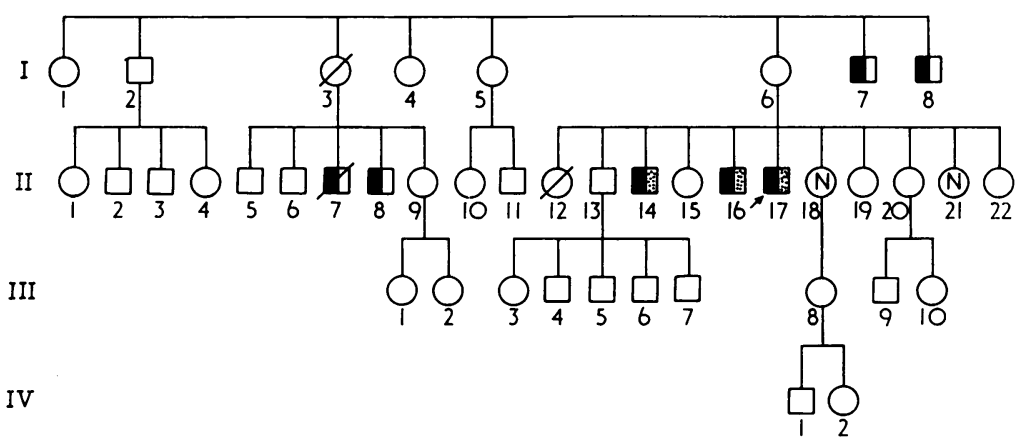

FIG. 4. Pedigree of Family D. 
Case II.12. He was severely retarded and had spent his life in a mental institution. He was aged 38 years, and is of shorter stature than his brothers but had good general development and no congenital abnormalities.

Case III.9. He was 14 years of age and had been in an institution for the retarded, since the age of 2 years. He was moderately retarded. Other family members were of normal intelligence.

\section{Family B (Fig. 2)}

Attention was drawn to this family because of mental retardation in two brothers, III.1 and III.2. Three generations of this family were studied.

Case II.2. He was admitted to a centre for the retarded at the age of 9 years. He died in the centre from status epilepticus at the age of 13 years. He was diagnosed as an 'imbecile of poor grade'.

Case II.3. A 41-year-old man who was admitted to an institution for the retarded at the age of 10 years and who had been institutionalized since then. He was moderately retarded.

Case II.4. This was a male child suffering from a congenital heart lesion. He died at $\mathbf{1 6}$ days of age.

Case III.1. A 20-year-old man who had been in an institution for the retarded since the age of 11 years. He had suffered from asthma and was an epileptic. He had large asymmetrical ears, and strabismus, large hands, and a high palate. He was moderately retarded.

Case III.2. A 9-year-old boy who was functioning at a moderately retarded level. He was living at home and attending a day centre for retarded children.

Case III.1 and III.2 had different fathers. Other family members were of normal intelligence.

\section{Family C (Fig. 3)}

As was the case with other families in this survey, this family was co-operative because they realized the possibility of inheritance of mental retardation through the female line.

Case II.2. A moderately retarded male who in childhood lived in an institution but who now resides at home. He was attending a sheltered workshop. He had a mild degree neuromuscular incoordination.

Case III.2. A moderately to mildly retarded boy aged 7 years who attended special school.

\section{Family D (Fig. 4)}

The propositus and two brothers were in the same institution. The case notes of these brothers stated that one maternal sister had two retarded sons and that the mother had two brothers who were retarded. Not all family members were available for investigation. Two retarded males had died before the beginning of this study.

Case 1.7. A man who always lived at home but who was said to have been 'very retarded'. He died in his 50's.
Case 1.8. A mildly retarded male who had been in an institution for the retarded but who was now living at home.

Case II.7. A male who was said to have been more retarded than the propositus but who had not been in an institution. He was deceased.

Case II.8. A man in his 60's who lived at home and was cared for by a sister. He was reported to have been retarded all his life.

Case II.14. A mildly retarded man now aged 58 years. He lived in an institution for the retarded, and was reported to have been epileptic as a child. He was of normal physical development.

Case II.16. A 59-year-old mildly retarded man who lived in a institution for the retarded. He had normal physical development.

Case II.17. A 60-year-old mildly retarded man who lived in an institution for the retarded. He was more retarded than II.14 and II.16. He had a history of occasional epileptic seizures, but had normal physical development.

\section{Results of chromosome analysis}

The appearance of the marker chromosome was variable (Fig. 5). In some metaphases it appeared as a distinct isochromatid break, with the acentric products of the break assuming varying positions in relation to the chromosome, but always in close proximity to it. In others it appeared as a chromatid break or as an endoreduplication of the break. All these forms were randomly represented in each subject.

The small size of the acentric fragment produced the appearance of a satellited chromosome. How-

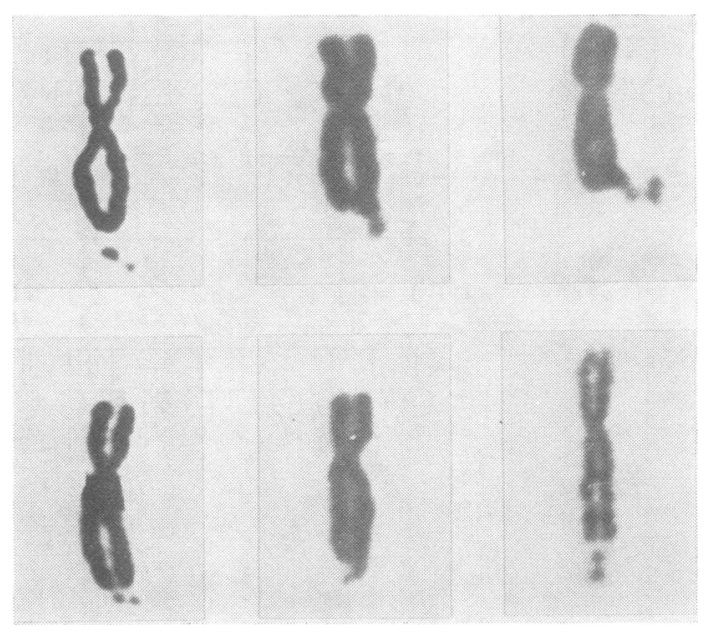

FIG. 5. Appearance of marker chromosome. 


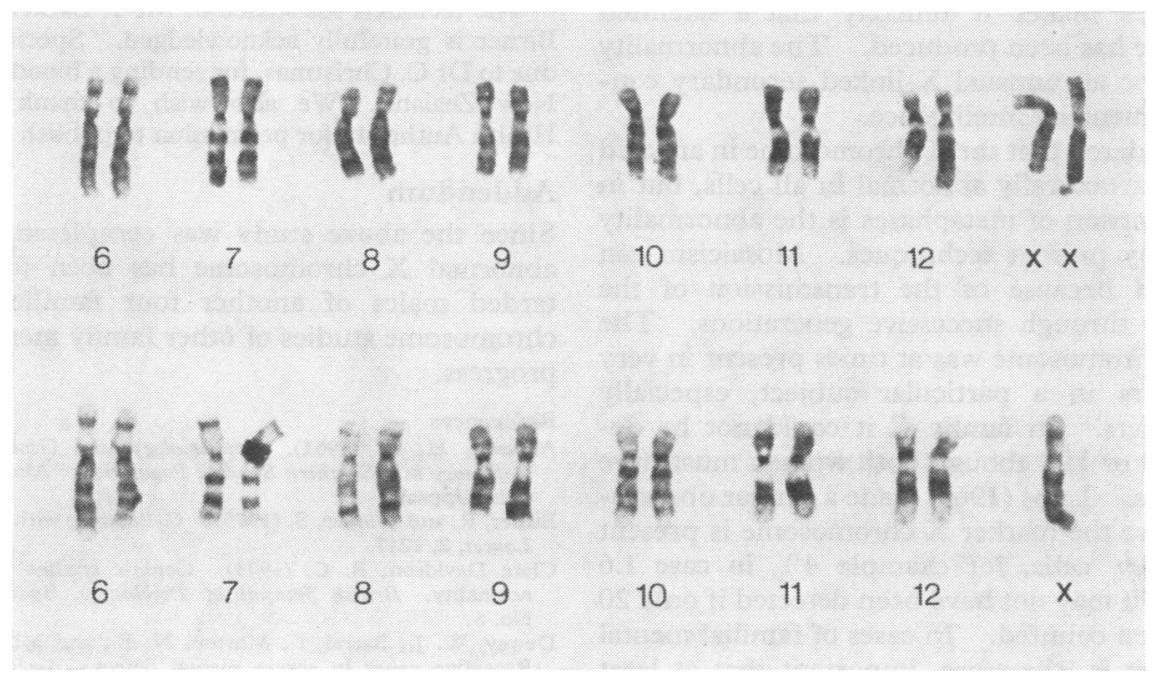

Fig. 6. Giemsa banded $\mathrm{C}$ group chromosomes from a female carrier and an affected male.

ever there was no satellite association with acrocentric chromosomes. The intensity of fluorescence of the terminal ends of the abnormal X chromosome with acridine orange, was the same as that of the terminal ends of normal X chromosomes.

With a culture time of 2 days, less than half the number of marker $\mathbf{X}$ chromosomes were found in 100 cells when compared with the standard culture time of 3 days. Similarly the number of marker $\mathbf{X}$ chromosomes were lower when the duration of colchicine treatment was prolonged beyond $2 \frac{1}{2}$ hours.

In all subjects with the marker $\mathrm{C}$ group chromosome, Giemsa banding showed that it was the $\mathrm{X}$ chromosome (Fig. 6). The site of the defect appears to be Xq 2.7 or Xq 2.8 .

The proportions of the marker chromosome in 100 metaphases of each subject are shown in Table. The marker chromosome was not detected in the mother and grandmother of family $\mathrm{C}$.

\section{Discussion}

Many authors have observed an excess of males in institutions for the mentally retarded (Penrose, 1954; Malzberg, 1953; Akesson, 1961; Dewey et al, 1965; Turner et al, 1971; Clare Davidson, 1973) and this has been the subject of a recent monograph (Lehrke, 1974). Additional arguments for the contribution of mental retardation to this male excess have been presented by Turner and Turner (1974) who recently carried out a survey in N.S.W. from which they estimated that X-linked forms of mental retardation were responsible for one-fifth of all mental retardation in the IQ range 30 to 35 . They referred to the growing number of case reports of X-linked mental retardation, unaccompanied by somatic or biochemical defect. The families in our study have much in common with this group, often referred to as Renpennings' syndrome, but in addition an $\mathrm{X}$ chromosome abnormality is present in retarded males and female carriers. In the 4 families studied, mental retardation was confined to males who were essentially phenotypically normal. The marker X chromosome was shown in all available live retarded males in approximately $30 \%$ of metaphases, though this proportion varied considerably.

Fluctuation in the number of abnormal metaphases was observed in males whose blood was cultured on different occasions and particularly when culture time and colchicine time was varied. In preparations where the chromosomes were contracted through prolonged treatment with colchicine the marker $\mathrm{X}$ chromosome was more difficult to detect. Variation in the appearance of the abnormal X chromosome and in particular the variability induced by changing cultural conditions suggests the labile nature of the abnormality.

The nature of the abnormality is not known. Since the intensity of fluorescence of the terminal bands with acridine orange was unchanged, neither translocation nor deletion appears to have occurred. The absence of satellite association with acrocentric 
chromosomes makes it unlikely that a satellited chromosome has been produced. The abnormality appears to be an unusual X-linked secondary constriction influencing intelligence.

It is considered that the $\mathrm{X}$ chromosome in affected subjects is structurally abnormal in all cells, but in only a proportion of metaphases is the abnormality detectable by present techniques. Mosaicism can be excluded because of the transmission of the abnormality through successive generations. The marker $\mathrm{X}$ chromosome was at times present in very low numbers in a particular subject, especially female carriers. In family $C$ it could not be detected in I.1 or II.1 though both women must have been carriers. Lubs (1969) made a similar observation. Where the marker $\mathrm{X}$ chromosome is present in only a few cells, for example $4 \%$ in case I.6 (Family A), it may not have been detected if only 20 cells had been counted. In cases of familial mental retardation it is, therefore, important that at least 100 metaphases are analysed. We also wish to emphasize the importance of recording apparently minor chromosomal abnormalities even if their clinical significance is not known at the time of observation. Small breaks and similar details should not be dismissed as artefacts and minor structural defects should be recorded even if they are not reported. As with other chromosome abnormalities the marker $\mathrm{X}$ chromosome is detected more easily when the preparation is of high quality.

The risk of a female carrier having a retarded son appears to be greater than 50\% (Dunn et al, 1962/ 1963; Renpenning et al, 1962). This was also the case in our 4 families, where 20 of 28 sons born to female carriers were mentally retarded.

With a history of familial mental retardation involving males, a careful search for the marker $\mathrm{X}$ chromosome should be made so that appropriate genetic counselling can be given. When female carriers become pregnant amniocentesis is indicated.
The technical assistance of $\mathrm{Mr}$ I. Barker and Mrs R. Birner is gratefully acknowledged. Special thanks are due to $\mathrm{DrC}$. Christmas, for sending a blood sample from New Zealand. We also wish to thank the Mental Health Authority for permission to publish this paper.

\section{Addendum}

Since the above study was completed a similarly abnormal $\mathrm{X}$ chromosome has been found in retarded males of another four families. Further chromosome studies of other family members are in progress.

\section{References}

Akesson, H. O. (1961). Epidemiology and Genetics of Mental Deficiency in a Southern Swedish Population. Almqvist and Wiksells, Uppsala.

Birner, R. and Wiener, S. (1975). G-Banding with heat treatment. Lancet, 2, 1217.

Clare Davidson, B. C. (1973). Genetic studies in mental subnormality. British fournal of Psychiatry, Special Publication No. 8.

Dewey, W. J., Barrai, I., Morton, N. E., and Mi, M. P. (1965) Recessive genes in severe mental defect. American fournal of Human Genetics, 17, 237-256.

Dunn, H. G., Renpenning, H., Gerrard, J. W., Miller, J. R., Tabata, T., and Federoff, S. (1962/1963). Mental retardation as a sexlinked defect. American fournal of Mental Deficiency, 67, 827848 .

Dutrillaux, B. (1973). Nouveau systeme de marquage chromosomique; les bandes T. Chromosoma (Berlin), 41, 395-402.

Lehrke, R. G. (1974). X-linked mental retardation and verbal disability. Birth Defects Original Article Series, Vol. X, No. 1.

Lubs, H. A. (1969). A marker X chromosome. American fournal of Human Genetics, 21, 231-244.

Malzberg, B. (1953). Sex differences in the prevalence of mental deficiency. American fournal of Mental Deficiency, 58, 301-305.

Martin, J. P. and Bell, J. (1943). A pedigree of mental defect showing sex-linkage. Fournal of Neurology and Psychiatry, 6, 154-157.

Penrose, L. S. (1954). The Biology of Mental Defect, 2nd ed., pp. 163-174. Sidgwick and Jackson, London.

Renpenning, H., Gerrard, J. W., Zaleski, W. A., and Tabata, T. (1962). Familial sex-linked mental retardation. Canadian Medical Association fournal, 87, 954-956.

Roboz, P. and Pitt, D. (1969). Studies on 782 cases of mental deficiency. Part IV. Australian Paediatric Fournal, 5, 137-148.

Snyder, R. D. and Robinson, A. (1969). Recessive sex-linked mental retardation in the absence of other recognizable abnormalities. Clinical Pediatrics, 8, 669-674.

Turner, G. and Turner, B. (1974). X-linked mental retardation. Fournal of Medical Genetics, 11, 109-113.

Turner, G., Turner, B., and Collins, E. (1971). X-linked mental retardation without physical abnormality. Renpenning's syndrome. Developmental Medicine and Child Neurology, 13, 71-78. 